\title{
Effect of Technological Innovation Inputs on Global Value Chains Status
}

\author{
Shuili Yang, Xian University of Technology, China \\ Yang Yi, Xian University of Technology, China
}

\begin{abstract}
Under the backdrop of the continuous escalation of the Sino-U.S. trade friction, China's industrial development environment in global value chains (GVCs) has further deteriorated, research on the improvement GVC status of the Chinese manufacturing industry has become the focus of attention for industry and academia. The direction of $R \& D$ inputs are of utmost importance to the improvement of GVC status. However, comparatively little attention has been paid to this topic in existing studies. Following the production activity decomposition framework and combining with the World InputOutput Tables, the action mechanism of R\&D inputs on GVC status from two aspects of industrial value-added and embedding position were analyzed, the moderating effect of digital servitization was demonstrated. Results show that: The input of applied research has inverted U-shaped influence on the industrial value-added, while it has U-shaped influence on embedding position; The input of basic research has U-shaped influence on the industrial value-added, while it has inverted U-shaped influence on embedding position; The moderating effect of digital servitization between R\&D inputs and GVC status is significant, in the short term, the digital servitization can not only magnify the promotion effect of the applied research inputs on GVC status, but also shorten the lag period of basic research inputs on GVC status. In the long run, the digital servitization can not only weaken the marginalization trend of the applied research inputs on GVC status, but also enhance the positive feedback effect of basic research inputs on GVC status. This study is important for China to improve the GVC status.
\end{abstract}

\section{KEYWORDS}

GVC Embedding Position, Industrial Value-Added, Industrialization, Integration of Information, Technological Innovation

\section{INTRODUCTION}

The value added dividends released by the mature technology foundation of developed countries is approaching threshold, China's manufacturing industry has been gradually locked in the low-end of global value chains (hereinafter referred to as GVCs). The industrial value-added growth rate of Chinese manufacturing industry has been declining since 2002, and just $21.17 \%$ percent in 2018 , which was more than $10 \%$ lower than that of the United States, Germany, Japan and other developed countries (Strategic consulting center of the Chinese Academy of Engineering. 2020). Under the 
backdrop of the continuous escalation of the Sino-U.S. trade friction, China's industrial development environment in GVCs has further deteriorated. In February 2020, the United States proposed measures to ban the transport of Leading Edge Aviation Propulsion-1C (LEAP-1C) turbofan engines and limit the Honeywell flight control system to China. In May 2020, the United States issued new regulations prohibiting China's Huawei Technologies Co., Ltd. and its suppliers from using U.S. technology and software. How to improve the GVC status of Chinese manufacturing industry has become the focus of attention for industry and academia. For example, after being listed as an "enterprise on the export control entity list", Huawei started to use "Hi-Silicon chips" and the "Harmony operating system" to reduce its dependence on U.S. high-tech intermediate products, and extensively implement collaborative research and development (hereinafter referred to as R\&D) activities with ST microelectronics, Audi, BYD and other enterprises for the technological independent. Duan et al. (2018) proposed to increase R\&D inputs of domestic intermediate products can realize import substitution and industrial upgrading in GVCs

Viewed from the perspective of industrial upgrading in GVCs, although increasing R\&D inputs is the main force for Chinese manufacturing industry to realize industrial autonomy and get rid of lock in the low-end of GVCs, they lack pertinence because of the fuzzy definition of the GVC status. For example, In Duan et al. (2018), the upgrading of China's position in GVCs was quantified by the decrease of the vertical specialization share, the strategy of increasing R\&D inputs of the domestic intermediate products to decline the vertical specialization share neglected the change of embedding position in GVCs. Prete and Rungi (2017) found that both midstream and downstream parents tend to integrate affiliates that are more proximate in segments of a supply chain, probably due to $R \& D$ complementarities in adjacent industries. In Prete and Rungi (2017), producers of intermediate inputs that can integrate either backward or forward along the chain will affect the the embedding position of an industry in GVCs, however the R\&D complementarities effect of integrating affiliates on industrial value-added is similarly neglected. In fact, improving the GVC status for the manufacturing industry means a process by which the industry rises from a low value-added peripheral position to a high value-added central position, that is to say, industrial value-added and the embedding position, as two important dimensions of upgrading in GVCs, are indispensable to positioning the GVC status, however, comparatively few related studies comprehensively consider the two dimensions. Therefore, especially important is studying the impact of collaborative innovation on GVC status from both two aspects of the industrial value-added and embedding position.

Globalization and investment in information and communication technologies have generally increased enterprise productivity (Tang et al., 2020). With the rapid development of artificial intelligence (AI), big data, cloud computing, fifth-generation (5G) and other digital communication technologies, the global service trade is also accelerating the process of digitization. In 2020, digital service trade has accounted for more than half of global service trade. Under the new trend of digital servitization, the primary content of our study is how the moderating effect of the digital servitization between collaborative innovation and GVC status.

\section{LITERATURE REVIEW}

The existing literature mainly analyzed the improvement of GVC status from the following two aspects.

Increasing the domestic value added ratio (DVAR). Following the value-added trade accounting framework as proposed by Koopman et al. (2014), DVAR is widely used as an important index to reflect the industrial value-added capacity in GVCs, existing studies generally deem that imported intermediate inputs and trade liberalization are important factors to affect changes in the DVAR. From the perspective of imported intermediate, imported intermediate inputs have large productivity effects (Halpern et al., 2015), Colantone and Crinò (2014) found new imported inputs had a strong positive effect on product creation in Europe, and it gave a substantial boost to output growth in manufacturing. Moreover, high quality of import intermediate input dynamically improved the firms' export DVAR 
in GVCs through independent, resulting in "markup effects" and "relative price effects" (Liu and Qiu, 2016; Chen et al., 2017). Bas and Strauss-Kahn (2015) suggested a scenario where firms exploit the input trade liberalization to upgrade the quality of their intermediate inputs in order to upgrade the quality of their exported products. From the perspective of trade liberalization, trade liberalization greatly contributed to global and regional production fragmentation and the formation of production networks (Aichele and Heiland, 2018). Kee and Tang (2016) found that foreign direct investment (FDI) liberalization enhanced variety and competitiveness of domestically-produced inputs, which spurred the increase in the processing firms' DVAR, Brandt and Morrow (2017) show that the increase in China's aggregate DVAR was spurred by reductions in input tariffs with both the intensive and extensive margins playing roles. Using a multi-sector structural gravity model with input-output linkages, Johnson and Noguera (2017) showed that declines in bilateral trade frictions associated with regional trade agreements (RTAs) explained changes in bilateral value added to export ratios, moreover, the spread of RTAs over time enhanced value added exports rising between $29-39 \%$ and gross exports rising between $37-50 \%$ in the long run.

Improving the embedding position in GVCs. Under the capture-type and hierarchical-type governance mechanisms of existing GVCs (Humphrey and Schmitz, 2002), emerging countries can only embedding in the subordinate position to accept the price, quality, security and environmental standards governance from developed countries, once emerging countries tend to realize highend function upgrading and cross-chain upgrading, the developed countries will strengthen the previously mentioned governance measures, forcing the emerging countries to lock in the low-end of GVCs (Gibbon et al., 2008). How to improve the embedding position of emerging countries in GVCs has become the focus of attention for academia, existing literature has made great efforts to quantify the embedding position in GVCs. For example, Hummels et al. (2001) proposed vertical specialization (VS) to calculate the imported inputs in producing goods that are exported, then Koopman et al. (2010) used the share of VS in gross exports to measure the extend of one countrysector involved in GVCs, and the GVC participation index were correspondingly constructed. Antràs et al. (2012) explored a measure of industry "upstreamness" (or distance from final-good production) based on the notion that industries selling a disproportionate share of their output to relatively upstream industries should be relatively upstream themselves, they constructed this measure by using the U.S. Input-Output Tables instead of the World Input-Output Tables. Then, Miller and Temurshoev (2017) proposed input "downstreamness" measure based on the World Input-Output Tables to quantify industry relative position, respectively, along the global output supply chain and the global input demand chain, furthermore, they found the increase in output "upstreamness"/input "downstreamness" for most countries over time was driven by a rise in cross-border intermediates sales/purchases. Wang et al. (2017a, 2017b) developed a new set of country-sector level indicators of GVC characteristics in terms of average production length, and relative the measure of industry "upstreamness" on a production network was improved. Ding et al. (2019) adopted GVC indicators proposed by Wang et al to verify the impact of US anti-dumping against China on China's manufacturing GVC status.

Existing research still has the following deficiencies. First, current studies on increasing the DVAR mostly unfold from the perspective of imported intermediate inputs and trade liberalization, and comparatively few pay attention to internal factors such as R\&D inputs. However, the impact of imported intermediate inputs and trade liberalization on DVAR will suffer great losses under the backdrop of the continuous escalation of Sino-U.S. trade friction. Second, current studies mainly focused on how to quantify industry embedding position in GVCs and the relative influencing factors were neglect. In fact, the measure of quantifying industry DVAR and "upstreamness" based on valueadded trade accounting framework gives us an enrich research foundation to position the GVC status from the perspectives of industrial value-added and the embedding position, this study will rely on above mentioned measure to make up for these deficiencies. 
The remainder of this study is organized as follows. Section 3 describes theoretical analysis and research hypothesis. Section 4 describes the measurement model and data processing. Section 5 describes the the descriptive statistical analysis and empirical results. Section 6 presents conclusions.

\section{THEORETICAL ANALYSIS AND RESEARCH HYPOTHESIS}

\subsection{R\&D Inputs and GVCs Status}

$R \& D$ inputs is the main force to promote industrial innovation and economic growth, while the accumulation of basic research and applied research are two important direction of R\&D inputs (Romer, 1990). Following the model of Abernathy and Utterback (1978), there are three stages in the technological evolution of a successful enterprise in developed countries: flexible stage, intermediate stage, and mature stage. However, the industrial development of emerging countries always starts from mature stage by undertaking international industries and technology transfer, it means the technological evolution of manufacturing industries of emerging countries presents the characteristics of typical inverse Abernathy and Utterback model. In the intermediate stage, emerging countries participate in GVCs mainly based on comparative advantage of low-cost, and form a preliminary production capacity through introducing and acquiring advanced technology (Álvarez and Torrecillas, 2020). At the same time, increasing the input of applied research not only can accelerate the industrial learning speed of product modularization and function modularization, guiding the industries to achieve the deep value-added space from product upgrading to process upgrading or even function upgrading. but also expand the market scope and the life cycle of mature technology, the distance between emerging countries manufacturing industries and final consumption keeps shortening, the trend of GVC status under the increasingly input of applied research is shown as process I in Figure 1.

On the contrary, basic research is not the appropriate input direction in the primary stage of industrial development. The high experimental cost and time cost of basic research indicate that the profit compensation can not return in the short time, and the excessive input in basic research will form a "crowding out effect" on applied research (Prettner and Werner, 2016). In addition, the weak technological foundation can not guarantee the commercial transformation and practical application of basic research, the technological progress effect of basic research is difficult to realize. The trend of GVC status under the increasingly input of basic research is shown as process III in Figure 2. In the intermediate stage of the technological evolution, basic research gradually become the core abilities for technological competition, however, it needs to go through the lag period of market demand inertia adjustment, industry's technology preparation and technological innovation replacement, hence, the trend of GVC status will continue the process III as shown in Figure 2.

Figure 1. The trend of GVC status under the increasingly input of applied research

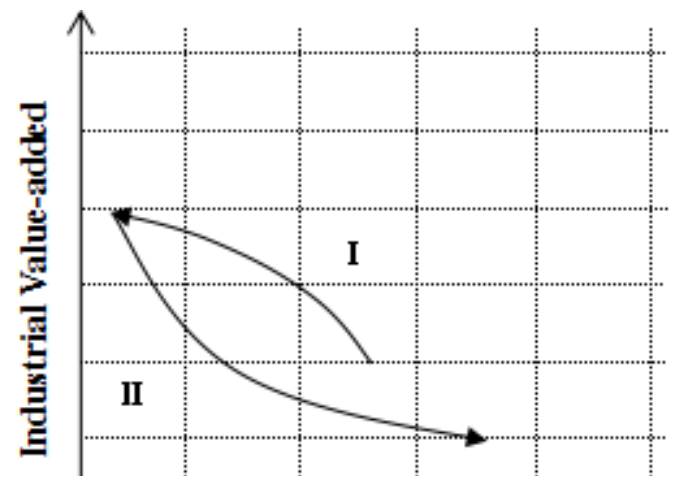


Figure 2. The trend of GVC status under the increasingly input of basic research

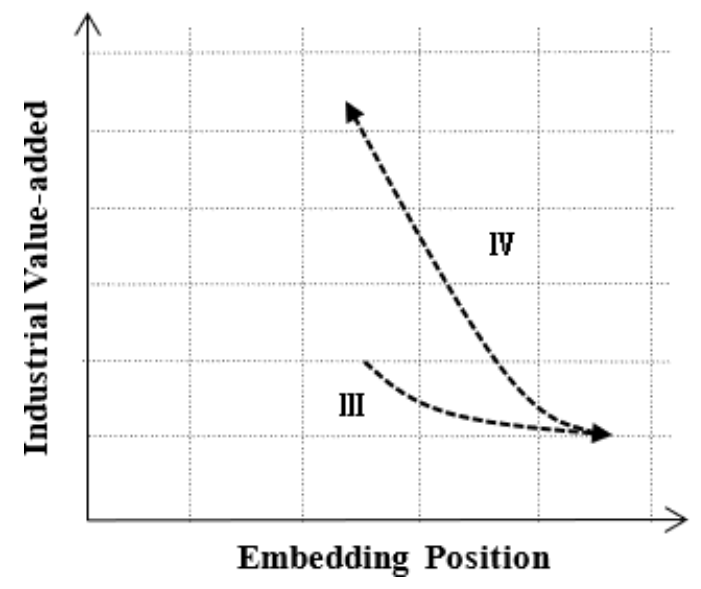

In the flexible stage of the technological evolution, the importation and imitation cost has been rapidly increasing with the continuous decrease of technology gap between emerging countries and the developed countries. To ensure the long-term existence of technology gap and consolidate the governance status in GVCs, the developed countries will narrow the technology spillover channel by implementing strict technology transfer threshold and improving product standards and quality requirements, the emerging countries will eventually fall into the vicious cycle of "technology importation to applied research then to technology imitation". In addition, with the basic research gradually become the key capabilities of industrial development, relying on the applied research can not make up the technology gap, on the contrary, increasing the input of applied research will not only induce "innovation bubble", leading to the "structural contradiction" between the rapid increase of utility model patents and the continuous decline of total factor productivity, but also strengthen the dependence on the existing technological routes, forcing the industries of emerging countries to lock-in the low value-added end. Moreover, the existing value-added space is constantly occupied by new entrants, the distance between industries and final consumption is correspondingly widened, the embedding position is turning to the upstreamness of GVCs, the trend of GVC status under the increasingly input of applied research is shown as process II in Figure 1.

Relying on the "knowledge accumulation effect" of basic research on innovation growth, the "technology absorption effect" of basic research on applied research, the "innovation incentive effect" of basic research on technological frontier (Gersbach et al., 2018), manufacturing industries of emerging countries can build sustainable technological innovation ability in the flexible stage of the technological evolution. On the one hand, increasing the input of basic research can strengthen the linkage between manufacturing industries and $R \& D$ organizations to foster industrial innovation, and improve the industry's excavation and positioning abilities in the value-added space of GVCs, manufacturing industries of emerging countries will eventually form a sustainable development circle of industrial value-added feedback for basic research. On the other hand, increasing the input of basic research can enhance the industry to embed in the central position of global innovation chain and capture network rents in GVCs, manufacturing industries of emerging countries will eventually realize a sustainable development circle of embedding position feedback for basic research, the trend of GVC status under the increasingly input of basic research is shown as process IV in Figure 2. Based on this, the following hypothesis is constructed:

H1: A nonlinear relationship exists between R\&D inputs and GVC status. 


\subsection{The Moderating Effect of the Digital Servitization}

The application of digital technologies can further advance servitization by enabling sophisticated and novel service offerings (Ardolino et al., 2018), the digital servitization enable new serviceoriented business models (Adrodegari and Saccani, 2017), it makes possible for enterprises to connect consumer, supplier and retailer by using digital technology, such as the Artificial Intelligence (AI), Internet of Things (IOT), Cloud Computing, fifth-generation wireless systems (5G) and so on. The moderating effect of the digital servitization between R\&D inputs and GVC status can be understood from the following three aspects.

The demand creation effect of digital servitization. The digital servitization effectively helps manufacturing industry to capture consumer preferences and personalized demand information through the collection of the consumers' browse, purchase, use and evaluation data (Allmendinger and Lombreglia, 2005). For applied research, accurately meeting consumer demands by the digital servitization extends the promotion effect of the applied research inputs on GVC status in process I; furthermore, the digital servitization helps manufacturing industry to explore a variety of derived demands based on the mature technology, for example, the digital servitization helps medical diagnostic device manufacturers to develop intelligent wearable terminal. Therefore, the digital servitization can weaken the marginalization trend of the applied research inputs on GVC status in process II. For basic research, predicting the potential demand of consumers by digital servitization provides the direction for basic research, hence, carrying out digital servitization can greatly shorten the lag period of basic research inputs on GVC status in process III; moreover, the demand creation activities based on the simultaneous exploration and exploitation by digital servitization significantly promote the sustainable development circle of basic research inputs on GVC status in process IV.

The business process re-engineering effect of digital servitization. The digital servitization effectively helps manufacturing industry to expand their business filed, such as mass customization, modular products rapid configuration, and remote maintenance service. For applied research, optimizing inventory business process by digital servitization not only reduce the transportation and inventory cost, but also improve the response speed to meet customer demand, the promotion effect of the applied research inputs on GVC status in process I is enlarged; the establishment of the remote operation and maintenance system by digital servitization helps enterprises to monitor and analyze the use of products, as well as diagnose products fault in time, manufacturing enterprises transform from providing products to products and services (Grubic, 2018). The value-added space of mature technology is extended, and the distance between industry and final consumption is shortened, it indicates that the negative effect of the applied research inputs on GVC status in process II will be weakened by the moderating effect of the digital servitization. For basic research, relying on the digital servitization tools such as digital simulation, manufacturing enterprises can easily realize the connection of virtual manufacturing environment and simulation design environment. Simulating the optimal performance parameters of the product significantly reduces trial and error cost, and improves the efficiency of basic research, the lag period of basic research inputs on GVC status in process III will be correspondingly declined; developing the digital technology such as 3D-printing, Virtual Reality (VR), Augmented Reality (AR) means manufacturing enterprises have lots of opportunities to integrate different subject areas like mathematics, chemistry, physics, it greatly expands the field of basic research for new technology and products, and the promotion effect of basic research inputs on GVC status in process IV will be relatively enhanced.

The supply chain collaboration effect of digital servitization. The digital servitization can effectively help manufacturing industry to eliminate the information barrier among consumer, supplier and retailer, it makes possible for the collaboration of all sides in supply chains to participate in the product design, production, storage and sales through digital platforms such as intelligent terminals, online platforms and virtual design environments, the flexibility and intelligence level of supply chains will eventually be improved. For applied research, the digital servitization promotes the collaboration 
of consumer, supplier and retailer to meet the customers' personalized and diversified demands, and the promotion effect of the applied research inputs on GVC status in process I will be enhanced; the digital servitization guides the collaboration of producer service enterprises and manufacturing enterprises to provide the "Date-Service-Product package" to customer, it extends the application situation of mature technology, and effectively reduce the negative impact of the applied research inputs on GVC status in process II. For basic research, the digital servitization leads the collaboration of all sides along with supply chains to formulate a series of digital standards such as technical standard, quality standard, design standard, safety standard and environmental protection standard, it greatly consolidate the basic research technology foundation and avoid R\&D risks, the lag period of basic research inputs on GVC status in process III will be correspondingly declined; the digital servitization promotes the collaboration of enterprises in different industries, functions and regions to construct supply chain network, the traditional linear supply chain will be substituted (Paschou et al., 2020), and the value-added space created by the exchange and integration of different knowledge interface in the supply network will enhance the positive feedback effect of basic research inputs on GVC status in process IV. Based on this, the following hypothesis is constructed:

H2: The digital servitization plays a significant moderating role between R\&D inputs and GVC status.

\section{MEASUREMENT MODEL AND DATA PROCESSING}

\subsection{Measurement Model}

The following econometric model is constructed to test the action mechanism of R\&D inputs on GVC status, and the moderating effect of the digital servitization. Industries at different technological levels are grouped and tested:

$$
\begin{aligned}
G V C \text { status }_{i t}= & \alpha_{0}+\alpha_{1} R D_{-} \text {input }_{i t}+\alpha_{2} \text { Digital_ser }_{i t}+\alpha_{3} R D_{-} \text {input }_{i t} \times \text { Digital_ser }_{i t} \\
& +\alpha_{4} R D_{-} \text {input }{ }_{i t}^{2}+\alpha_{5} R D_{-} \text {input }_{i t}^{2} \times \text { Digital_ser }_{i t}+\alpha_{6} \text { Indus_Demand }_{i t} \\
& +\alpha_{7} \text { Indus_Scale }_{i t}+\alpha_{8} \text { Indus_Conce }_{i t}+\varepsilon_{i t}
\end{aligned}
$$

where $G V C_{-}$Status $_{i t}$ represents the $i$ industry GVC status in $t$ period, which is quantified via industrial value-added (Value_added) and embedding position (Emd_pos); RD_input represents the applied research inputs/basic research inputs of $i$ industry in $t$ period, meanwhile, introducing the square term $R D_{-}$input $^{2}$ to reflect the long-term effect of applied research inputs/ basic research inputs. Digital_ $s e r_{i t}$ represents the degree of digital servitization of $i$ industry in $t$ period; Indus_Demand ${ }_{i t}$ represents industrial effective demand scale; Indus_Scale ${ }_{i t}$ represents the industrial scale of $i$ industry in $t$ period; Indus _ Conce $_{i t}$ represents the degree of industrial concentration of $i$ industry in $t$ period.

\subsection{Data Processing}

\subsubsection{GVC Status}

As mentioned above, we quantify the status of one country-sector participation in GVCs from two aspects of industrial value-added and embedding position.

Following the production activity decomposition framework as proposed by Wang et al. (2017a, 2017b), we can obtain the decomposition of domestic value-added and final production simultaneously as follows: 


$$
\hat{V} B \hat{Y}=\hat{V} L \hat{Y^{D}}+\hat{V} L \hat{Y^{F}}+\hat{V} L A^{F} B \hat{Y}=\hat{V} L \hat{Y^{D}}+\hat{V} L \hat{Y^{F}}+\hat{V} L A^{F} L \hat{Y^{D}}+\hat{V} L A^{F}\left(B \hat{Y}-L Y^{D}\right)
$$

where $X$ is the gross output column vector, $A$ is the domestic input coefficient matrix, $A^{D}$ is a diagonal block matrix of domestic input coefficient, $A^{F}$ is an off-diagonal block matrix of imported input coefficient, $A^{F}=A-A^{D}, Y$ is a column vector of final goods and services production, $Y^{D}$ is a column vector of final goods and services production for domestic consumption, $Y^{F}$ is a column vector of final products exports, $Y^{F}=Y-Y^{D}, E$ is a column vector of gross exports, $\hat{V}$ is the diagonal matrix of direct value-added coefficient, $\mathrm{B}$ is the well-known Leontief inverse matrix, $L=\left(I-A^{D}\right)^{-1}$ and is defined as the local Leontief inverse matrix.

The row vector of the matrix $V B Y$ represents the distribution of value-added created from one country-sector that is absorbed by final goods production in all country-sectors. Summing up Equation (2) along the row direction, we can decompose value-added generated from each sector pair in terms of where it goes:

$$
V a^{\prime}=\hat{V} B Y=\hat{V} L Y^{D}+\hat{V} L Y^{F}+\hat{V} L A^{F} L Y^{D}+\hat{V} L A^{F}\left(B Y-L Y^{D}\right)
$$

where $\hat{V} L Y^{D}$ represents value-added produced at home and absorbed by domestic final demand without involving international trade; $\hat{V} L Y^{F}$ are domestic value-added embodied in final product exports, it represents value-added in terms of where it goes. $\hat{V} L A^{F} L Y^{D}$ is the domestic value-added embodied in a country-sector's intermediate exports that is used by the direct importing country to produce its domestic product, which is consumed in that country. $V L A^{F} B Y-L Y^{D}$ ) is the domestic value-added from a country-sector that is embodied in its intermediate exports and used by a direct importing country to produce exports (intermediate or final) for other countries. The sum of the last three terms in Equation (3) equals domestic value-added in gross exports ( $D V A$ ), as proposed by Koopman et al. (2014).

Following the decomposition formula in Equation (3), the industrial value-added (Value _added ) can be measured using domestic value-added as a share of total export:

Value_added $=\frac{D V A}{\text { Export }}=\frac{\hat{V} L Y^{F}+\hat{V} L A^{F} L Y^{D}+\hat{V} L A^{F}\left(B Y-L Y^{D}\right)}{\text { Export }}$

Following the decomposition formula in Equation (2), the method of general "average valueadded propagation lengths" provides a unified framework to measure the embedding position of GVCs, and the embedding position ( Emd_ pos ) can be expressed as follows:

$$
E m d_{-} \text {pos }=\frac{E^{T} \cdot\left[\hat{V} \cdot\left(B^{2}-B\right)\right] \cdot Y}{E^{T} \cdot[\hat{V} B] \cdot Y}
$$


where $E^{T}$ is the column vector composed of 0 and 1 elements, the value of the country-sector under investigation is 1 , otherwise it is 0 . The larger the embedding position index value is, the closer the country-sector embedding in the upstream of GVCs.

The previously described data originate from the 2016 version of the World Input-Output Table. Given the timeliness of empirical analysis, the average growth rate of relevant indicators from 2012 to 2014 is used to estimate the data for the three years from 2015 to 2017. According to the International Standard Industrial Classification (ISIC Rev. 4), the manufacturing industries are aggregated as Table 1 shows. Combined with the completeness and comparability of the data, the $\mathrm{r} 23$ machinery and equipment repair and installation industry is culled, r20 and r21 are merged into the transport equipment manufacturing industry, and the remaining 17 industries are used as research samples.

\subsubsection{R\&D Inputs}

As mentioned above, the input of applied research and basic research are two main directions of R\&D inputs. Referring to the the measurement of applied research inputs and basic research inputs used by Tool (2012), we choose the proportion of industry applied research stock to the total industrial output to reflect the input intensity of applied research, the applied research stock can be expressed as follows:

$$
\text { Applied_stock } k_{i t}=\text { Applied__flow }_{i t}+\sum_{j=1}^{n}(1-\delta)^{j} \text { Applied _flow }_{i(t-j)}
$$

Table 1. The classification of manufacturing industries based on R\&D intensities

\begin{tabular}{|c|c|c|}
\hline Industries classification & Industry(ISIC Rev.4) & Code \\
\hline \multirow{6}{*}{ Low-tech industries } & Food products, beverages and tobacco products & r5 \\
\hline & Textiles,wearing apparel and leather products & r6 \\
\hline & Wood and wood products & r7 \\
\hline & Paper and paper products & r8 \\
\hline & Printing and reproduction of recorded media & r9 \\
\hline & Furniture & $\mathrm{r} 22$ \\
\hline \multirow{6}{*}{ Medium-tech industries } & Coke and refined petroleum products & $\mathrm{r} 10$ \\
\hline & Chemicals and chemical products & $\mathrm{r} 11$ \\
\hline & Rubber and plastic products & $\mathrm{r} 13$ \\
\hline & Other non-metallic mineral products & $\mathrm{r} 14$ \\
\hline & Basic metals & $\mathrm{r} 15$ \\
\hline & Fabricated metal products, except machinery and equipment & $\mathrm{r} 16$ \\
\hline \multirow{5}{*}{ High-tech industries } & Basic pharmaceutical products and pharmaceutical preparations & r12 \\
\hline & Computer, electronic and optical products & $\mathrm{r} 17$ \\
\hline & Electrical equipment & $\mathrm{r} 18$ \\
\hline & Machinery and equipment n.e.c. & r19 \\
\hline & Transport equipment & $\mathrm{r} 20+21$ \\
\hline
\end{tabular}

Source: Authors' arrangement 


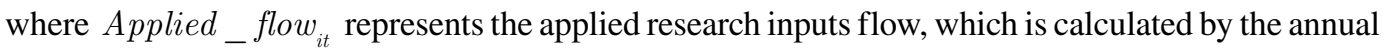
R\&D inputs flow data of $i$ industry in $t$ period, $\delta$ represents the R\&D depreciation rate, and the applied research depreciation rate is taken as $20 \%$.

The measurement of basic research inputs intensity is similar to that of applied research, and the basic research stock can be expressed as follows:

$$
\text { Basic _ }_{\text {stock }}=\text { Basic }_{-} \text {flow }_{t}+\sum_{j=1}^{n}(1-\delta)^{j} \text { Basic }_{-} \text {flow }_{(t-j)}
$$

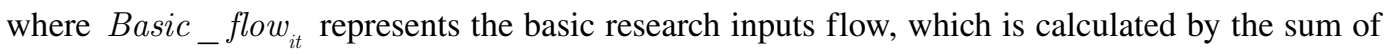
basic research funds of universities and research institutions in each year, and the basic research depreciation rate $\delta$ is taken as 0 . The data are from the annual Scientific and Technological Activities of Industrial Enterprises Statistical Yearbook.

\section{DIGITAL SERVITIZATION}

Based on the World Input-Output Tables, intermediate input can be divided by product sector and service sector. The degree of the digital servitization in $s$ Country $k$ sector situation is shown in formula (8):

$$
\text { Inform_ }_{-}{ }_{n d u s}^{s}=\sum_{g}^{42} \sum_{j}^{2} V_{j}^{g} B_{j k}^{g s}
$$

where $V$ is the $1 \times N$ vector of value-added coefficient, $B$ is Leontief inverse matrix, $j$ represents the digital servitization sector, such as "Telecommunications", and "Computer programming, consultancy and related activities; information service activities".

\subsection{Control Variable}

Industrial demand, the industrial demand is expressed by the proportion of new product sales revenue to the actual investment; Industrial scale, the industrial scale is expressed by the proportion of the industry main business revenue to total manufacturing industry main business income; Industry concentration. the industry concentration is expressed by the share of gross output value of large and medium-sized enterprises in its relative industry. The data are from the annual Chinese Statistical Yearbook.

\section{RESULTS}

\subsection{The Descriptive Statistical Analysis}

The status of Chinese manufacturing industry integration into GVCs. Introducing the United States, German and Japanese manufacturing industries for a comparative analysis, and the specifics are as shown from Figure $3 \mathrm{a}$ to $3 \mathrm{~d}$. These figures are divided into four quadrants by the global mean of embedding position(1.53) and industrial value-added (0.12).

Figure 3a shows that almost all the industries with different technology levels fall into the fourth quadrants, the rapid increase in the embedding position and the continued weakening of industrial value-added mean that China's status in GVCs will continue to be marginalized. 
Figure $3 \mathrm{~b}$ shows that most high-tech U.S. manufacturing industries fall into the second quadrants, and most low-tech and medium-tech industries are distributed in the third quadrants and fourth quadrants respectively. Moreover, high-tech industries have a significant upward trend to high value-added links in the midstream of GVCs, medium-tech industry's value-added level reaches approximately the global mean, while the upgrading trend of GVCs status of low-tech industries is weak.

Figure $3 \mathrm{c}$ shows that most of the industries in German fall into the first and second quadrants. Among them, low-tech and high-tech industries have a significant upward trend to high value-added links in the midstream of GVCs, and medium-tech industries have a significant upward trend to high value-added links in the upstream of GVCs.

Figure $3 \mathrm{~d}$ shows that most Japanese industries fall into the second quadrants and fourth quadrants. Moreover, high-tech industries have a significant upward trend to high value-added links in the midstream of GVCs, medium-tech industry's value-added level reaches approximately the global mean, and low tech have a significant upward trend to the global mean of industrial value-added in the upstream of GVCs.

Before the hypothesis testing, the descriptive statistics of variables and the stationary of sample data are tested firstly, as Table 2 shows, the results show that the sample data is stable.

Figure 3. The status of the Chinese, U.S., German, and Japanese manufacturing industries in GVCs

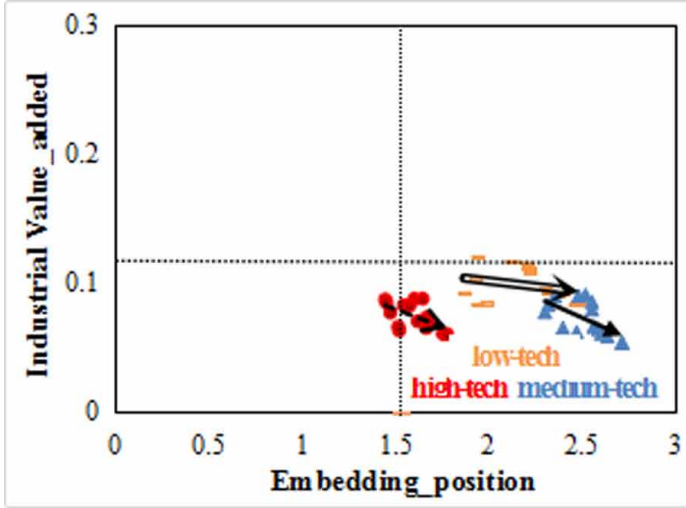

(3a)

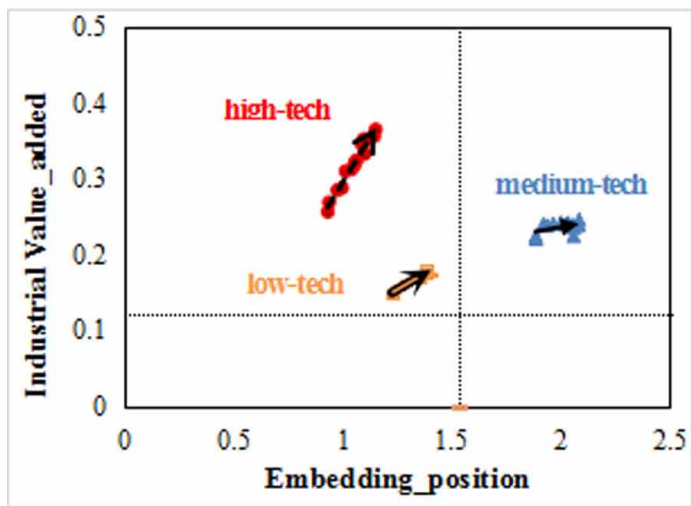

(3c)

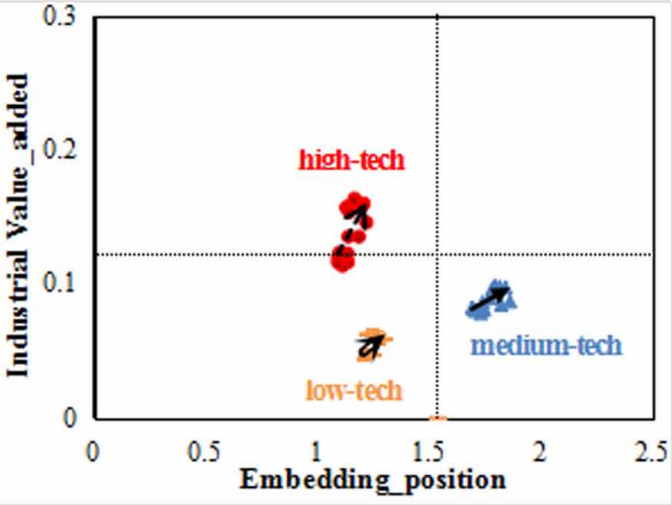

(3b)

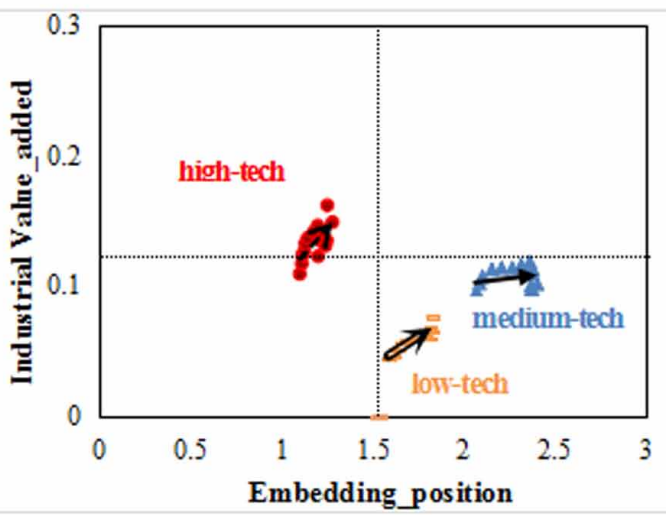

(3d) 
Table 2. The descriptive statistics of variables and the stationary of sample data

\begin{tabular}{|l|l|l|l|l|l|}
\hline \multicolumn{1}{|c|}{ Variables } & \multicolumn{1}{c|}{ Mean } & \multicolumn{1}{c|}{ S.D. } & \multicolumn{1}{c|}{ LLC } & \multicolumn{1}{c|}{ IPS } & \multicolumn{1}{c|}{ ADF } \\
\hline Value_added & 0.084 & 0.052 & $-6.84 * * *$ & $-2.07 * *$ & $-58.63^{* * *}$ \\
\hline Emd_pos & 2.112 & 0.710 & $-6.05^{* * *}$ & $-1.74 * *$ & $-62.84^{* * * *}$ \\
\hline Apllied_research & 0.001 & 0.001 & $-5.41^{* * *}$ & $-2.01^{* *}$ & $-67.52^{* * *}$ \\
\hline Basic_research & 0.004 & 0.004 & $-6.01 * * *$ & $-2.00^{* * *}$ & $-67.52^{* * *}$ \\
\hline Digital_Ser & 0.003 & 0.002 & $-4.45^{* * *}$ & $-2.45^{* * *}$ & $-72.31^{* * *}$ \\
\hline Indus_Dem & 2.204 & 2.363 & $-2.39 * * *$ & $-1.83^{* *}$ & $-67.65^{* * *}$ \\
\hline Indus_Scale & 0.058 & 0.040 & $-4.18^{* * *}$ & $-1.25^{*}$ & $-56.28^{* * *}$ \\
\hline Indus_Conce & 0.468 & 0.195 & $-2.17 * *$ & $-1.98^{* *}$ & $-85.47 * * *$ \\
\hline
\end{tabular}

Note: ${ }^{*}<0.1, p<0.05^{\star *}, p<0.01^{* * *}$

\subsection{Empirical Results}

Regression results of the R\&D inputs and GVCs status. In order to eliminate the influence of heteroscedasticity and sequence auto-correlation, we use the Hausman test to determine whether to select fixed or random effects model. The regression results are shown in Table 3.

As Table 3 shows, the input of applied research has a significant positive influence on industrial value-added, while the square item of applied research inputs has a significant negative influence on industrial value-added, it represents the input of applied research has inverted U-shaped influence on industrial value-added. The input of applied research has a significant negative influence on

Table 3. Regression results of the R\&D inputs and GVCs status

\begin{tabular}{|c|c|c|c|c|c|c|c|c|}
\hline \multirow{4}{*}{ Variables } & (1) & (2) & (3) & (4) & (5) & (6) & (7) & (8) \\
\hline & Value_added & Emd_pos & Value_added & Emd_pos & Value_added & Emd_pos & Value_added & Emd_pos \\
\hline & FE & RE & FE & FE & GMM & GMM & GMM & GMM \\
\hline & \multicolumn{2}{|c|}{ Apllied_research } & \multicolumn{2}{|c|}{ Basic_research } & \multicolumn{2}{|c|}{ Apllied_research } & \multicolumn{2}{|c|}{ Basic_research } \\
\hline RD_input & $\begin{array}{l}6.09 * * * \\
(16.52)\end{array}$ & $\begin{array}{l}-132.28 * * * \\
(-7.15)\end{array}$ & $\begin{array}{l}-6.79 * * * \\
(-6.45)\end{array}$ & $\begin{array}{l}63.13 * * * \\
(6.85)\end{array}$ & $\begin{array}{l}2.56 * * * \\
(6.27)\end{array}$ & $\begin{array}{l}-53.30 * * * \\
(-3.80)\end{array}$ & $\begin{array}{l}-6.39 * * * \\
(-4.86)\end{array}$ & $\begin{array}{l}53.12 * * * \\
(9.14)\end{array}$ \\
\hline RD_input ${ }^{2}$ & $\begin{array}{l}-1090.39 * * \\
(-2.00)\end{array}$ & $\begin{array}{l}24723.9 * * * \\
(5.67)\end{array}$ & $\begin{array}{l}278.11^{* * * *} \\
(3.10)\end{array}$ & $\begin{array}{l}-3837.3 * * * \\
(-4.89)\end{array}$ & $\begin{array}{l}-496.79 * * \\
(-2.02)\end{array}$ & $\begin{array}{l}6394.27 * * \\
(2.54)\end{array}$ & $\begin{array}{l}362.2 * * * \\
(1.66)\end{array}$ & $\begin{array}{l}-3230.6^{* * * *} \\
(-4.23)\end{array}$ \\
\hline Indus_Dem & $\begin{array}{l}0.003^{* *} * \\
(2.17)\end{array}$ & $\begin{array}{l}-0.05 * * * \\
(-4.60)\end{array}$ & $\begin{array}{l}0.001^{*} \\
(1.63)\end{array}$ & $\begin{array}{l}-0.07 * * * \\
(-7.00)\end{array}$ & $\begin{array}{l}0.003^{* * * *} \\
(16.45)\end{array}$ & $\begin{array}{l}-0.04 * * * \\
(-3.62)\end{array}$ & $\begin{array}{l}0.002 * * * \\
(3.68)\end{array}$ & $\begin{array}{l}-0.001 \\
(-0.18)\end{array}$ \\
\hline Indus_Scale & $\begin{array}{l}0.17 \\
(1.33)\end{array}$ & $\begin{array}{l}-4.88 * * * \\
(-4.88)\end{array}$ & $\begin{array}{l}0.29 * * \\
(2.41)\end{array}$ & $\begin{array}{l}-7.10 * * * \\
(-6.82)\end{array}$ & $\begin{array}{l}0.10 \\
(1.26)\end{array}$ & $\begin{array}{l}2.05 \\
(1.00)\end{array}$ & $\begin{array}{l}0.04 \\
(0.46)\end{array}$ & $\begin{array}{l}4.35 * * * \\
(2.91)\end{array}$ \\
\hline Indus_Conce & $\begin{array}{l}0.06^{* * * *} \\
(3.07)\end{array}$ & $\begin{array}{l}0.74 * * * \\
(4.57)\end{array}$ & $\begin{array}{l}0.12 * * * \\
(5.95)\end{array}$ & $\begin{array}{l}0.46^{* *} \\
(2.55)\end{array}$ & $\begin{array}{l}-0.05 * * * \\
(-9.76)\end{array}$ & $\begin{array}{l}0.12 \\
(1.63)\end{array}$ & $\begin{array}{l}0.29^{*} \\
(1.82)\end{array}$ & $\begin{array}{l}-1.61 * * \\
(-4.62)\end{array}$ \\
\hline Cons & $\begin{array}{l}0.04 * * * \\
(3.37)\end{array}$ & $\begin{array}{l}2.11 * * * \\
(11.51)\end{array}$ & $\begin{array}{l}0.001 \\
(0.10)\end{array}$ & $\begin{array}{l}2.51 * * * \\
(22.42)\end{array}$ & $\begin{array}{l}0.05 * * * \\
(7.89)\end{array}$ & $\begin{array}{l}0.59 * * * \\
(2.83)\end{array}$ & $\begin{array}{l}0.03 * * \\
(2.13)\end{array}$ & $\begin{array}{l}1.25^{* * *} * \\
(7.72)\end{array}$ \\
\hline $\mathrm{N}$ & 306 & 306 & 306 & 306 & 255 & 255 & 255 & 255 \\
\hline Within- $\mathrm{R}^{2}$ & 0.13 & 0.57 & 0.26 & 0.56 & $\mathrm{AR}(1)=0.00$ & $\operatorname{AR}(1)=0.01$ & $\mathrm{AR}(1)=0.06$ & $\mathrm{AR}(1)=0.01$ \\
\hline F/Wald & $434.50 * * *$ & $307.02 * * *$ & $16.05^{* * *}$ & $58.80 * * *$ & $\operatorname{AR}(2)=0.32$ & $\mathrm{AR}(2)=0.33$ & $\operatorname{AR}(2)=0.13$ & $\operatorname{AR}(2)=0.44$ \\
\hline \multirow{2}{*}{ Hausman test } & $\mathrm{Ch} 2=12.63$ & $\mathrm{Ch} 2=3.92$ & $\mathrm{Ch} 2=8.46$ & $\mathrm{Ch} 2=22.13$ & \multirow{2}{*}{ Sargan $=0.56$} & \multirow{2}{*}{ Sargan $=0.61$} & \multirow{2}{*}{ Sargan $=0.85$} & \multirow{2}{*}{ Sargan $=0.83$} \\
\hline & Prob $=0.01$ & Prob $=0.27$ & Prob $=0.08$ & Prob $=0.00$ & & & & \\
\hline
\end{tabular}

Note: ${ }^{*}<<0.1, p<0.05^{\star *}, p<0.01^{* * *}$ 
embedding position, while the square item of applied research inputs has a significant negative influence on embedding position, it indicates the input of applied research has U-shaped influence on embedding position. Similar to the previous analysis, we can also find the input of basic research not only has U-shaped influence on industrial value-added, but also has inverted U-shaped influence on embedding position. In summary, a nonlinear relationship exists between R\&D inputs and GVC status. Therefore, Hypotheses 1 is support. In order to avoid endogeneity problem, we further employ the GMM dynamic panel-data estimator suggested by Arellano and Bond (1991) to test the robustness of the results, the inclusions of lagged dependent variables do not change most results. In all cases, the Sargan test ensures the validity of instruments used, and the Arellano-Bond test for second order autocorrelation is accepted in each specification. Therefore, the model is correctly specified.

Considering the heterogeneity of industry, industries with different technological levels are grouped and tested. As Table 4 shows, in low-tech industries, the inverted U-shaped relationship between the input of applied research and industrial value-added is not significant, while the applied research inputs has U-shaped influence on embedding position, it represents applied research inputs mainly affects GVC status by embedding position. The input of basic research has a significant negative influence on industrial value-added, and a significant positive influence on embedding position, while the correlation of the square item of basic research inputs on GVC status is not significant, it represents low-tech industries still in the lag period of process III; in medium-tech industries, the correlation of the square item of R\&D inputs and GVC status is not significant, R\&D inputs and GVC status only show liner relationship, it represents medium-tech industries still in the process I and III; in high-tech industries, the conclusions for high-tech industries are similar to those of the full-sample industry.

The moderating effect of the digital servitization between R\&D inputs and GVC status. As Table 5 shows, the symbol of applied research inputs is same as that of the interaction term of applied research inputs and the degree of the digital servitization, while the symbol of the square item of applied research inputs is opposite to that of the interaction term of the square item of applied research inputs and the degree of the digital servitization, it represents the digital servitization can not only magnify the promotion effect of the applied research inputs on industrial value-added in process I, but also weaken the negative effect of the applied research inputs on industrial value-added in process II.

The symbol of basic research inputs is opposite to that of the interaction term of basic research inputs and the degree of the digital servitization, while the symbol of the square item of basic research inputs is same as that of the interaction term of the square item of basic research inputs and the degree of the digital servitization, it represents the digital servitization can not only shorten the lag period of basic research inputs on industrial value-added in process III, but also enhance the promotion effect of basic research inputs on industrial value-added in process IV.

Similar to the previous analysis, for the input of applied research, we find digital servitization weakens the downstream trend in process I, and upstream trend in process II of the applied research inputs on embedding position. For the input of basic research, digital servitization not only weakens the upstream trend in process III, but also extend the downstream trend in process IV. In summary, The digital servitization plays a significant moderating role between R\&D inputs and GVC status. Therefore, Hypotheses 2 is support.

\section{CONCLUSION}

To study the action mechanism of R\&D inputs on GVC status, and demonstrate the moderating effect of digital servitization, we follow the production activity decomposition framework based on 2016 Release of the World Input-Output Tables, and quantify the GVC status from two aspects of industrial value-added and embedding position. The conclusions are as follows:

1. The input of applied research has inverted U-shaped influence on the industrial value-added, while it has U-shaped influence on embedding position. 
Table 4. Regression results of the R\&D inputs and GVCs status with different technological levels

\begin{tabular}{|c|c|c|c|c|c|c|c|c|c|c|c|c|}
\hline \multirow{5}{*}{ 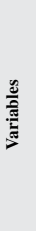 } & (1) & (2) & (3) & (4) & (5) & (6) & (7) & (8) & (9) & (10) & (11) & (12) \\
\hline & $\begin{array}{l}\text { Value } \\
\text { added }\end{array}$ & Emd_pos & $\begin{array}{l}\text { Value } \\
\text { added }\end{array}$ & Emd_pos & $\begin{array}{l}\text { Value } \\
\text { added }\end{array}$ & Emd_pos & $\begin{array}{l}\text { Value } \\
\text { added }\end{array}$ & Emd_pos & $\begin{array}{l}\text { Value_ } \\
\text { added }\end{array}$ & Emd_pos & $\begin{array}{l}\text { Value } \\
\text { added }\end{array}$ & Emd_pos \\
\hline & $\mathbf{F E}$ & FE & FE & FE & FE & FE & FE & FE & FE & $\mathbf{F E}$ & FE & $\mathbf{F E}$ \\
\hline & Apllied & esearch & \multicolumn{2}{|c|}{ Basic_research } & \multicolumn{2}{|c|}{ Apllied_research } & \multicolumn{2}{|c|}{ Basic_research } & \multicolumn{2}{|c|}{ Apllied_research } & \multicolumn{2}{|c|}{ Basic_research } \\
\hline & \multicolumn{4}{|c|}{ Low_tech } & \multicolumn{4}{|c|}{ Medium_tech } & \multicolumn{4}{|c|}{ High_tech } \\
\hline 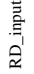 & $\begin{array}{l}2.04 \\
(0.46)\end{array}$ & $\begin{array}{l}-147.79^{\text {**** }} \\
(-4.51)\end{array}$ & $\begin{array}{l}-8.70^{*} \\
(-1.83)\end{array}$ & $\begin{array}{l}98.14 * * * * \\
(2.64)\end{array}$ & $\begin{array}{l}7.09^{*} \\
(1.86)\end{array}$ & $\begin{array}{l}-175.79^{* * * *} \\
(-5.60)\end{array}$ & $\begin{array}{l}-7.52^{* * * *} \\
(-6.65)\end{array}$ & $\begin{array}{l}70.10^{* * * *} \\
(5.95)\end{array}$ & $\begin{array}{l}12.95^{* * * *} \\
(2.92)\end{array}$ & $\begin{array}{l}-200.98^{* * * *} \\
(-4.51)\end{array}$ & $\begin{array}{l}-1.45 \\
(-0.83)\end{array}$ & $\begin{array}{l}23.99 \\
(1.11)\end{array}$ \\
\hline 咅 & $\begin{array}{l}-163.30 \\
(-0.17)\end{array}$ & $\begin{array}{l}23573.8^{* * * *} \\
(3.29)\end{array}$ & $\begin{array}{l}463.76 \\
(0.40)\end{array}$ & $\begin{array}{l}-1931.29 \\
(-0.21)\end{array}$ & $\begin{array}{l}-2497.65 \\
(-1.41)\end{array}$ & $\begin{array}{l}25074.5^{*} \\
(1.72)\end{array}$ & $\begin{array}{l}-349.84 \\
(-1.21)\end{array}$ & $\begin{array}{l}-838.79 \\
(-0.28)\end{array}$ & $\begin{array}{l}-2157.46^{* * *} \\
(-2.32)\end{array}$ & $\begin{array}{l}41654.9 * * * * \\
(4.89)\end{array}$ & $\begin{array}{l}62.31 \\
(0.21)\end{array}$ & $\begin{array}{l}-57.78 \\
(-0.03)\end{array}$ \\
\hline 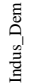 & $\begin{array}{l}0.003 \\
(1.54)\end{array}$ & $\begin{array}{l}-0.08^{* * *} \\
(-4.89)\end{array}$ & $\begin{array}{l}0.001 \\
(0.43)\end{array}$ & $\begin{array}{l}-0.08^{* * * *} \\
(-5.71)\end{array}$ & $\begin{array}{l}0.004 \\
(1.50)\end{array}$ & $\begin{array}{l}-0.01 \\
(-0.42)\end{array}$ & $\begin{array}{l}0.01^{* * * *} \\
(1.63)\end{array}$ & $\begin{array}{l}-0.06^{* * * *} \\
(-3.21)\end{array}$ & $\begin{array}{l}-0.01^{*} \\
(-1.96)\end{array}$ & $\begin{array}{l}0.05 \\
(1.56)\end{array}$ & $\begin{array}{l}0.001 \\
(0.27)\end{array}$ & $\begin{array}{l}-0.02 \\
(-0.60)\end{array}$ \\
\hline 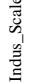 & $\begin{array}{l}0.70^{*} \\
(1.88)\end{array}$ & $\begin{array}{l}-0.14 \\
(-0.05)\end{array}$ & $\begin{array}{l}0.74 * * \\
(2.31)\end{array}$ & $\begin{array}{l}-3.70 \\
(-1.47)\end{array}$ & $\begin{array}{l}0.13 \\
(0.55)\end{array}$ & $\begin{array}{l}-3.75^{* *} \\
(-2.02)\end{array}$ & $\begin{array}{l}0.34 * * \\
(2.26)\end{array}$ & $\begin{array}{l}-3.82^{* *} \\
(-2.45)\end{array}$ & $\begin{array}{l}0.05 \\
(0.25)\end{array}$ & $\begin{array}{l}-5.10^{\text {**** }} \\
(-3.02)\end{array}$ & $\begin{array}{l}0.76^{* * * *} \\
(5.11)\end{array}$ & $\begin{array}{l}-7.74 * * * \\
(-4.00)\end{array}$ \\
\hline $\begin{array}{l}\mathscr{y} \\
\tilde{z} \\
\tilde{J}^{\prime} \\
\tilde{\Xi}_{\Xi}^{\prime}\end{array}$ & $\begin{array}{l}0.16^{* * * *} \\
(3.95)\end{array}$ & $\begin{array}{l}1.17 \text { **** } \\
(3.87)\end{array}$ & $\begin{array}{l}0.26^{* * * *} \\
(5.29)\end{array}$ & $\begin{array}{l}0.55 \\
(1.44)\end{array}$ & $\begin{array}{l}-0.01 \\
(-0.26)\end{array}$ & $\begin{array}{l}0.36 \\
(1.26)\end{array}$ & $\begin{array}{l}0.08^{* * *} \\
(2.40)\end{array}$ & $\begin{array}{l}-0.02 \\
(-0.06)\end{array}$ & $\begin{array}{l}0.06^{*} \\
(1.88)\end{array}$ & $\begin{array}{l}0.74 * * * * \\
(2.76)\end{array}$ & $\begin{array}{l}-0.00 \\
(-0.01)\end{array}$ & $\begin{array}{l}0.77^{* * * * *} \\
(2.77)\end{array}$ \\
\hline$\tilde{\tilde{z}}$ & $\begin{array}{l}0.02 \\
(0.93)\end{array}$ & $\begin{array}{l}1.62 * * * * \\
(9.74)\end{array}$ & $\begin{array}{l}-0.04 \\
(-1.48)\end{array}$ & $\begin{array}{l}2.38^{* * * *} \\
(11.54)\end{array}$ & $\begin{array}{l}0.07 \\
(4.36)\end{array}$ & $\begin{array}{l}2.63 * * * \\
(18.94)\end{array}$ & $\begin{array}{l}0.01 \\
(0.48)\end{array}$ & $\begin{array}{l}2.94 * * * * \\
(17.14)\end{array}$ & $\begin{array}{l}0.03 \\
(1.47)\end{array}$ & $\begin{array}{l}1.59^{* * * *} \\
(8.33)\end{array}$ & $\begin{array}{l}0.03 * \\
(1.74)\end{array}$ & $\begin{array}{l}1.57 * * * * \\
(7.18)\end{array}$ \\
\hline $\mathrm{z}$ & 126 & 126 & 126 & 126 & 90 & 90 & 90 & 90 & 90 & 90 & 90 & 90 \\
\hline 嵒 & 0.25 & 0.65 & 0.35 & 0.65 & 0.22 & 0.58 & 0.49 & 0.56 & 0.19 & 0.64 & 0.10 & 0.54 \\
\hline 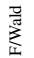 & $5.18^{* * * *}$ & $28.71 * * *$ & $8.60^{* * *}$ & $29.50 * * *$ & $4.36^{* * * *}$ & $22.07^{* * * *}$ & $15.17^{* * *}$ & $20.38^{* * *}$ & $3.05^{* * *}$ & $22.74 * * *$ & $70.42 * * *$ & $15.30^{* * * *}$ \\
\hline & $\mathrm{Ch} 2=29.16$ & $\mathrm{Ch} 2=59.40$ & $\mathrm{Ch} 2=10.20$ & $\mathrm{Ch} 2=11.49$ & $\mathrm{Ch} 2=10.98$ & $\mathrm{Ch} 2=34.40$ & $\mathrm{Ch} 2=21.38$ & $\mathrm{Ch} 2=20.51$ & $\mathrm{Ch} 2=37.68$ & $\mathrm{Ch} 2=12.06$ & $\mathrm{Ch} 2=13.84$ & $\mathrm{Ch} 2=33.78$ \\
\hline $\begin{array}{l}\overline{\text { n }} \\
\text { 胥 }\end{array}$ & Prob $=0.00$ & Prob $=0.00$ & Prob $=0.02$ & Prob $=0.01$ & Prob $=0.00$ & Prob $=0.00$ & Prob $=0.08$ & Prob $=0.00$ & Prob $=0.00$ & Prob $=0.01$ & Prob $=0.00$ & Prob $=0.00$ \\
\hline
\end{tabular}

Note: ${ }^{*}<0.1, p<0.05^{* *}, p<0.01^{* * *}$

2. The input of basic research has U-shaped influence on the industrial value-added, while it has inverted U-shaped influence on embedding position.

3. The moderating effect of digital servitization between R\&D inputs and GVC status is significant. In the short term, the digital servitization can not only magnify the promotion effect of the applied research inputs on GVC status in process I, but also shorten the lag period of basic research inputs on GVC status in process III. In the long run, the digital servitization can not only weaken the marginalization trend of the applied research inputs on GVC status in process II, but also enhance the positive feedback effect of basic research inputs on GVC status in process IV. 
Table 5. Regression results of the moderating effect of the digital servitization between R\&D inputs and GVC status

\begin{tabular}{|c|c|c|c|c|}
\hline \multirow{4}{*}{ Variables } & (1) & (2) & (3) & (4) \\
\hline & Value_added & Emd_pos & Value_added & Emd_pos \\
\hline & FE & FE & FE & $\mathbf{R E}$ \\
\hline & \multicolumn{2}{|c|}{ Apllied_research } & \multicolumn{2}{|c|}{ Basic_research } \\
\hline RD_input & $\begin{array}{l}6.75^{* * * *} \\
(3.11)\end{array}$ & $\begin{array}{l}-143.13 * * * \\
(-7.48)\end{array}$ & $\begin{array}{l}-5.07 * * * \\
(-5.06)\end{array}$ & $\begin{array}{l}51.72 * * * \\
(5.48)\end{array}$ \\
\hline RD_input ${ }^{2}$ & $\begin{array}{l}-1360.25 * * * \\
(-2.74)\end{array}$ & $\begin{array}{l}26417.5 * * * \\
(5.94)\end{array}$ & $\begin{array}{l}252.83 * * \\
(2.57)\end{array}$ & $\begin{array}{l}-5824.91 * * * \\
(-6.24)\end{array}$ \\
\hline Digital_Ser & $\begin{array}{l}15.34 * * * \\
(4.04)\end{array}$ & $\begin{array}{l}6.96 \\
(0.22)\end{array}$ & $\begin{array}{l}19.91 * * * \\
(6.48)\end{array}$ & $\begin{array}{l}12.45 \\
(0.42)\end{array}$ \\
\hline $\begin{array}{l}\text { Digital_SerX } \\
\text { RD_input }\end{array}$ & $\begin{array}{l}3913.23 * * \\
(2.45)\end{array}$ & $\begin{array}{l}36762.01 * * \\
(2.28)\end{array}$ & $\begin{array}{l}828.18^{*} \\
(1.65)\end{array}$ & $\begin{array}{l}-10871.49 * * \\
(-2.29)\end{array}$ \\
\hline $\begin{array}{l}\text { Digital_SerX } \\
\text { RD_input }^{2}\end{array}$ & $\begin{array}{l}1.48 \mathrm{e}+06 * * \\
(2.02)\end{array}$ & $\begin{array}{l}-1.66 \mathrm{e}+07 * * * \\
(-2.58)\end{array}$ & $\begin{array}{l}32114.21 * \\
(0.45)\end{array}$ & $\begin{array}{l}-2.08 \mathrm{e}+06 * * * * \\
(-3.07)\end{array}$ \\
\hline Indus_Dem & $\begin{array}{l}0.01 * * * \\
(3.30)\end{array}$ & $\begin{array}{l}-0.03 * \\
(-1.78)\end{array}$ & $\begin{array}{l}-0.01 * * * \\
(3.69)\end{array}$ & $\begin{array}{l}-0.09 * * * \\
(-5.34)\end{array}$ \\
\hline Indus_Scale & $\begin{array}{l}0.09 \\
(0.79)\end{array}$ & $\begin{array}{l}-4.43 * * * \\
(-4.31)\end{array}$ & $\begin{array}{l}0.25^{* *} \\
(2.22)\end{array}$ & $\begin{array}{l}-6.27 * * * \\
(-6.10)\end{array}$ \\
\hline Indus_Conce & $\begin{array}{l}0.07 * * * \\
(3.82)\end{array}$ & $\begin{array}{l}0.71 * * * \\
(4.29)\end{array}$ & $\begin{array}{l}0.12 * * * \\
(6.39)\end{array}$ & $\begin{array}{l}0.29 \\
(1.59)\end{array}$ \\
\hline Cons & $\begin{array}{l}0.06^{* * * *} \\
(5.55)\end{array}$ & $\begin{array}{l}2.07 * * * \\
(20.58)\end{array}$ & $\begin{array}{l}0.02^{*} \\
(1.80)\end{array}$ & $\begin{array}{l}2.59 * * * \\
(15.69)\end{array}$ \\
\hline $\mathrm{N}$ & 306 & 306 & 306 & 306 \\
\hline Within- $\mathrm{R}^{2}$ & 0.33 & 0.59 & 0.39 & 0.59 \\
\hline F/Wald & $14.16^{* * *}$ & $40.72 * * *$ & $18.53 * * *$ & $315.41 * * *$ \\
\hline \multirow{2}{*}{ Hausman test } & $\mathrm{Ch} 2=15.92$ & $\mathrm{Ch} 2=8.05$ & $\mathrm{Ch} 2=21.27$ & $\mathrm{Ch} 2=4.59$ \\
\hline & Prob $=0.00$ & Prob $=0.05$ & Prob $=0.00$ & Prob $=0.21$ \\
\hline
\end{tabular}

Note: ${ }^{*} p<0.1, p<0.05^{* *}, p<0.01^{* * *}$

The conclusions of the study have enriched research on improving the GVC status of emerging countries manufacturing industries, the policy implications include following: First, in the primary stage of industrial development, manufacturing industries can rely on technological learning and application platform, such as enterprise Engineering Research Center (ERC), to learn and absorb advanced technology, once value-added dividend brought by applied research approaches the threshold, manufacturing industries can build dynamic innovation alliance among enterprises, universities and research services organizations, to guide the extension and diffusion of applied research to basic research. Second, although the basic research is not the appropriate input direction in the primary stage of industrial development, manufacturing industries can rely on key generic technology platform, such as State Key Laboratory, National Engineering Laboratory, National Science and Technological Resources Sharing Service Platform, to accelerate breakthroughs in frontier of basic research, furthermore, the relative trading markets and platforms for promoting the industrial application and market cultivation of basic research achievements should be constructed, guiding the manufacturing industries to establish a sustainable development circle of applied research feedback for basic research. Third, digital servitization plays a significant moderating role between R\&D inputs and GVC status. On the one hand, manufacturing industries should expand the import scale of digital 
service to introduce advanced digital technology such as Digital Twin, 3D-printing, Virtual Reality (VR) and Augmented Reality (AR) for the digital transformation and upgrading. On the other hand, manufacturing industries should expand the investment on digital infrastructure to consolidate the foundation of digital application, through the establishment of the digital demonstration enterprises list and relative joint cooperation platforms, the digital services industries and the industrial digital ecology should be cultivated.

Although results with significant policy implication are observed, the study still has several limitations, which may provide potential starting points for future research. First, our main variables data originate from the 2016 version of the World Input-Output Table, however, the database only covers 43 data from 2000-2014. Considering the timeliness of empirical analysis, the average growth rate of relevant indicators from 2012 to 2014 is used to estimate the data for the three years from 2015 to 2017. Hence, applying the Input-Output Table with high timeliness is a direction for further research. Second, we mainly searched for key factors that affect GVC status from the perspective of R\&D inputs. Innovation factors, such as independent innovation, integrated innovation, and collaborative innovation also impact GVC status of the Chinese manufacturing industry, and the impact of innovation factors is a direction for further research.

\section{ACKNOWLEDGMENT}

This work is supported by the National Social Science Foundation of China [grant number 19BJY096], the Science and Technology Plan of Soft Science Foundation of Xi' an [grant number 2019112113RKX005SF009-2], Innovation Capability Support Program of Shaanxi [grant number 2020KRM044], Doctoral Research Project of Yan'an University [grant number YDBK2020-08]. 


\section{REFERENCES}

Adrodegari, F., \& Saccani, N. (2017). Business models for the service transformation of industrial firms. Service Industries Journal, 37(1), 57-83. doi:10.1080/02642069.2017.1289514

Aichele, R., \& Heiland, I. (2018). Where Is the Value-added? Trade Liberalization and Production Networks. Journal of International Economics, 115(11), 130-144. doi:10.1016/j.jinteco.2018.09.002

Allmendinger, G., \& Lombreglia, R. (2005). Four strategies for the age of smart services. Harvard Business Review, 83(10), 131-134. doi:10.1177/1059601104267607 PMID:16250631

Álvarez, I., \& Torrecillas, C. (2020). Interactive Learning Processes and Mergers and Acquisitions in National System of Innovation. Transnational Corporations Review, 12(1), 63-81. doi:10.1080/19186444.2020.1735782

Antràs, P., Chor, D., Fally, T., \& Hillberry, T. (2012). Measuring The Upstreamness of Production and Trade Flows. The American Economic Review, 102(3), 412-416. doi:10.1257/aer.102.3.412

Ardolino, M., Rapaccini, M., Saccani, N., Gaiardelli, P., Crespi, G., \& Ruggeri, C. (2018). The Role of Digital Technologies for the Service Transformation of Industrial Companies. International Journal of Production Research, 56(6), 2116-2132. doi:10.1080/00207543.2017.1324224

Arellano, M., \& Bond, S. (1991). Some Tests of Specification for Panel Data: Monte Carlo Evidence and an Application to Employment Equations. The Review of Economic Studies, 58(2), 277-297. doi:10.2307/2297968

Bas, M., \& Strauss-Kahn, V. (2015). Input-Trade Liberalization, Export Prices and Quality Upgrading. Journal of International Economics, 95(2), 250-262. doi:10.1016/j.jinteco.2014.12.005

Brandt, L., \& Morrow, P. M. (2017). Tariffs and the Organization of Trade in China. Journal of International Economics, 104(6), 85-103. doi:10.1016/j.jinteco.2016.10.010

Chen, B. (2017). Upstreamness, Exports, and Wage Inequality: Evidence from Chinese Manufacturing Data. Journal of Asian Economics, 48(2), 66-74. doi:10.1016/j.asieco.2016.11.003

Colantone, L., \& Crinò, R. (2014). New Imported Inputs, New Domestic Products. Journal of International Economics, 92(1), 147-165. doi:10.1016/j.jinteco.2013.10.006

Ding, Y. B., Zhang, H. Y., \& Tang, S. T. (2019). The Impact of US Anti-dumping against China on China's Manufacturing Global Value Chains Status. Transnational Corporations Review, 11(4), 323-331. doi:10.1080 /19186444.2019.1682408

Duan, Y. W., Dietzenbacher, E., Jiang, X. M., Chen, X. K., \& Yang, C. L. (2018). Why Has China's Vertical Specialization Declined. Economic Systems Research, 30(2), 178-200. doi:10.1080/09535314.2018.1431610

Gersbach, H., Sorger, G., \& Amon, C. (2018). Hierarchical Growth: Basic and Applied Research. Journal of Economic Dynamics \& Control, 86(5), 178-184. doi:10.2139/ssrn.1465608

Gibbon, P., Bair, J., \& Ponte, S. (2002). Governing Global Value Chains: An Introduction. Economy and Society, 37(3), 315-338. doi:10.1080/03085140802172656

Grubic, T. (2018). Remote Monitoring Technology and Servitization: Exploring the Relationship. Computers in Industry, 100(12), 148-158. doi:10.1016/j.compind.2018.05.002

Halpern, L., Koren, M., \& Szeidl, A. (2015). Imported Inputs and Productivity. The American Economic Review, 105(2), 3360-3703. doi:10.1257/aer.20150443

Hummels, D., Ishii, J., \& Yi, K. M. (2001). The Nature and Growth of Vertical Specialization in World Trade. Journal of International Economics, 54(1), 75-96. doi:10.1016/S0022-1996(00)00093-3

Humphrey, J., \& Schmitz, H. (2002). How Does Insertion in Global Value Chains Affect Upgrading in Industrial Clusters? Regional Studies, 36(9), 1017-1027. doi:10.1080/0034340022000022198

Johnson, R. C., \& Noguera, G. (2012). Accounting for Intermediates: Production Sharing and Trade in Value Added. Journal of International Economics, 86(2), 224-236. doi:10.1016/j.jinteco.2011.10.003 
Kee, H. L., \& Tang, H. (2016). Domestic Value Added in Exports: Theory and Firm Evidence from China. The American Economic Review, 106(6), 1402-1436. doi:10.1257/aer.20131687

Koopman, R., Powers, W., Wang, Z., \& Wei, S. (2010). Give Credit Where Credit Is Due: Tracing Value Added in Global Production Chains. Available at: https://www.nber.org/papers/w16426/

Koopman, R., Wang, Z., \& Wei, S. J. (2014). Tracing Value-added and Double Counting in Gross Exports. The American Economic Review, 104(2), 459-494. doi:10.1257/aer.104.2.459

Liu, Q., \& Qiu, L. D. (2016). Intermediate Input Imports and Innovations: Evidence from Chinese Firms' Patent Filings. Journal of International Economics, 103(11), 166-183. doi:10.1016/j.jinteco.2016.09.009

Miller, R. E., \& Temurshoev, U. (2015). Output Upstreamness and Input Downstreamness of Industries/Countries in World Production. International Regional Science Review, 40(5), 443-475. doi:10.1177/0160017615608095

Paschou, T., Rapaccini, M., Adrodegari, F., \& Saccani, N. (2020). Digital Servitization in Manufacturing: A Systematic Literature Review and Research Agenda. Industrial Marketing Management, 89(8), $278-292$. doi:10.1016/j.indmarman.2020.02.012

Prete, D. D., \& Rungi, A. (2017). Organizing the Global Value Chain: A Firm-level Test. Journal of International Economics, 109(11), 16-30. doi:10.1016/j.jinteco.2017.08.003

Prettner, K., \& Werner, K. (2016). Why It Pays off to Pay Us Well: The Impact of Basic Research on Economic Growth and Welfare. Research Policy, 45(5), 1075-1090. doi:10.1016/j.respol.2016.03.001

Romer, P. M. (1990). Endogenous Technological Change. Journal of Political Economy, 98(5), 71-120. doi:10.1086/261725

Strategic Consulting Center of the Chinese Academy of Engineering. (2020). Report on the 2020 China Manufacturing Power Development Index: Report. Available at: http://tv.cctv.com/ 2020/01/01/ VIDEMyRgYQzWik3QPRdpRgzK200101.shtml/

Tang, J. M., Wang, W. M., \& Yu, Z. H. (2020). Globalization, ICT Investment and Firm Dynamism. Transnational Corporations Review, 12(2), 193-202. doi:10.1080/19186444.2020.1756724

Tool, A. A. (2012). The Impact of Public Basic Research on Industrial Innovation: Evidence from the Pharmaceutical Industry. Research Policy, 41(1), 1-12. doi:10.1016/j.respol.2011.06.004

Wang, Z., Wei, S., Yu, X., \& Zhu, K. (2017a). Measures of Participation in Global Value Chains and Global Business Cycles. Available at: https://www.nber.org/papers/w23222/

Wang, Z., Wei, S., Yu, X., \& Zhu, K. (2017b). Characterizing Global Value Chains: Production Length and Upstreamness. Available at: https://www.nber.org/papers/w23261/

William, J. A., \& James, M. U. (1978). Patterns of Innovation in Industry. Technology Review, 80(7), 40-47. doi:10.20801/jsrpim.3.4_555_2 